\title{
Front-office/back-office configurations and operational performance in complex health services
}

\author{
Paul Gemmel ${ }^{1}$, Thomas van Steenis ${ }^{2}, \&$ Bert Meijboom $^{3}$ \\ ${ }^{1}$ Center for Service Intelligence, Faculty of Economics and Business Administration, Ghent University, Belgium, ${ }^{2}$ Department of Organization \& \\ Strategy, and ${ }^{3}$ Department of Tranzo, Tilburg University, The Netherlands
}

\begin{abstract}
Background: Acquired brain injury $(\mathrm{ABI})$ occurs from various causes at different ages and leads to many different types of healthcare needs. Several Dutch ABI-networks installed a local co-ordination and contact point (CCP) which functions as a central and easily accessible service for people to consult when they have questions related to $A B I$.

Goals: To explore the relationship between front/back office design and operational performance by investigating the particular enquiry service provided by different CCPs for people affected by an $A B I$.

Methods: In-depth interviews with 14 FO/BO employees from three case organizations, complemented with information from desk research and three one-day field visits.

Results: The CCPs applied different FO/BO configurations in terms of customer contact and in terms of grouping of front and/or back office activities into tasks for one employee.

Discussion: It is the complexity of the enquiry that determines which approach is more appropriate. For complex enquiries, the level of decoupling is high in all CCPs. This allows multiple experts to be involved in the process. For regular enquiries, CCPs have a choice: either working in the same way as in the complex enquiries or coupling FO/BO activities to be able to serve clients faster and without handovers.
\end{abstract}

\section{Keywords}

Access to care, acquired brain injuries, complex health services, front-office/back office configurations, operational performance

\section{History}

Received 10 July 2013

Revised 14 October 2013

Accepted 10 November 2013

Published online 24 February 2014

\section{Introduction}

Yearly a lot of people are hurt by an acquired brain injury (ABI). This brain injury can occur from various causes, at different ages and can lead to different problems. The consequence is that there is a large variation in the healthcare needs of patients with $\mathrm{ABI}$ and that often many different healthcare providers are involved in the treatment. To guarantee continuity of care to a patient with $\mathrm{ABI}$, it is important that providers of healthcare such as family members, hospitals teams, community agencies and experts collaborate in an optimal way and that the co-ordination between these providers and the services they deliver is well managed $[1,2]$. To improve this collaboration and co-operation various networks have developed over time, linking ABI care providers together [3, 4]. In the Netherlands, 18 ABI-networks have been established in different regions during the previous years [5]. One of the major issues these networks are confronted with is the access to the network for patients who are in need of support. Therefore, these networks worked on new referral processes which can increase the timing and accessibility of services for their clients [6]. Several of the Dutch ABI-networks installed a local co-

Correspondence: Paul Gemmel, Center for Service Intelligence, Faculty of Economics and Business Administration, Ghent University, Tweekerkenstraat 2, 9000 Ghent, Belgium. Tel: +32 92643518. Fax: +32 92647888. E-mail: paul.gemmel@ugent.be ordination and contact point (CCP) which functions as a central and easily accessible service for people to consult when they have questions related to ABI. This CCP is active in the very beginning of the healthcare provision. It aims to advise and guide clients to the right healthcare provider and in this way make access to healthcare easier for patients with ABI.

When investigating the referral process to increase the timely access to services, two often opposite tendencies have to be accommodated. On the one hand, there is the broader societal trend to strengthen client-orientation in healthcare in the traditionally supply-driven system, where each entity provides only partial help. Often patient errors occur when a patient is treated by multiple professionals, or when transferred from one institution to another. On the other hand, many Western countries struggle with the high costs of their healthcare system. In this era of cost containment, healthcare providers are increasingly challenged to deliver high quality care in a cost-effective way. Put differently, healthcare services such as the CCPs in the ABI networks must be designed and managed in such a way that the limited resources are allocated to the right customer needs. As a result, there is a growing interest in using industrial processes or applying business concepts in patient care [7]. More specifically, care providers increasingly turn to the field of operations management (OM) to support their conversion from supply-based to demand-based service provision in 
order to find an efficient and effective answer to clients' needs and wants [8-10].

When designing service processes, healthcare organizations are confronted with a trade-off between increasing productivity and enhancing quality [11]. The presence of the customer (patient) in the service process is a major issue in dealing with this trade-off [12]. Traditionally, the field of operations management (OM) has suggested to make a distinction between processes that can be physically and/or temporally separated from the customer (back-office; BO) and processes that are performed when the customer is present (front-office; FO). The way in which the work is divided between $\mathrm{BO}$ and $\mathrm{FO}$, i.e. the $\mathrm{FO} / \mathrm{BO}$ configuration, can have an impact on the productivity and quality of the service provided and also on the timely access [13].

In this paper the relationship between front/back office design and operational performance (quality, costs and accessibility) is explored by investigating the particular enquiry service provided by different co-ordination and contact points (CCPs) for people who are affected by an acquired brain injury (ABI). The CCP of an ABI-network is charged with advising clients which healthcare provider to turn to. At the same time, the diversity in potential clients with different needs renders a high variety in the complexity of the enquiries. The various CCPs in the Dutch ABI-networks differ, however, in the front/back office design. Little pre-existing theory and knowledge is available on the effect of $\mathrm{FO} / \mathrm{BO}$ configurations on performance in healthcare provision, even though this phenomenon is considered as highly relevant [13]. This leads to the following research question: How does the front/back-office configuration of a CCP of an ABI-network influence the operational performance in the process of advising clients affected by an $\mathrm{ABI}$ ?

\section{Front/back office configuration}

This study defines FO work as being the activities in which direct contact between the client and the provider takes place, enabling interaction, whereas BO activities are activities where no contact with the client takes place. In this research, the design decisions concerning customer contact will be studied in combination with design decisions concerning task (de-)coupling. In turn, this combined perspective will be referred to as front/back office configuration.

\section{Customer contact decisions}

The customer contact decision is the decision how much customer contact is required in a particular service delivery process, or which activities are carried out with customer contact and which ones without' ([14], p. 111). Customer contact in service operations is discussed in the literature as early as 1978. Chase [15] explains how the extent of direct contact with customers in a service operation is influencing the ability to operate efficiently. Chase [15] originally defines direct contact with customers as the customer being physically present at the service operation. However, in more recent research it is suggested to define electronic interaction via, for example, email as customer contact too, as long as the opportunity for interaction is available [13]. In the remainder of this research, this broader and more up-to-date view of direct contact is used.

An organization can decide upon the extent of direct contact needed. This makes it possible to distinguish between high-contact and low-contact elements of the system [15]. Based upon the extent of direct contact with the customer, Chase [15] proposes to classify services into three groups. From high-contact to low-contact these groups are, according to Chase and Tansik [16]:

- Pure services: Production is carried out while the customer is present.

- Mixed services: A mix of face-to-face contact and back office work.

- Quasi-manufacturing: Almost no face-to-face contact.

In mixed services both high-contact and low-contact tasks are present. This makes it possible to split up the process into FO and $\mathrm{BO}$ tasks. The FO tasks consist of the part of the process in which high-contact is needed, while the BO consists of the tasks that need no or limited contact with the customer [16]. In the FO the activity is either performed by employees who are in direct contact with the customer or the activity is performed by the customers themselves [17].

\section{Customer contact: Impact on performance}

The extent of customer contact has an influence on operational performance. In the original introduction of the concept, the most important difference in performance between the $\mathrm{FO}$ and the $\mathrm{BO}$ is the potential to operate efficiently [15].

In the front-office, direct interaction with the customer is possible during the activity. This part of the system, thus, becomes more vulnerable to uncertainty, which makes it more difficult to control the process and operate efficiently [15]. However, in FO activities a company can excel in crossselling and in customizing and personalizing the service to the customer's needs [14]. In a healthcare context, new wishes and needs can be signalled earlier and services can be provided quickly and adapted to a wide range of client demands. Additional emotional support can also be provided in healthcare [13].

In the back-office, the technical part of delivering the service is separated from the environment. Since interaction with customers is not possible in this part of service creation, input uncertainty is reduced. BO activities are, thus, sealed off from uncertainty caused by customer contact, so that efficiency gains can be achieved [13, 14]. So, BO activities have the advantage of performance efficiency and the optimal use of resources [18]. In healthcare, consultations with peers usually take place in the back-office.

\section{(De-)coupling decision}

The (de-)coupling decision is the decision whether to separate activities in a process by splitting them up into different jobs executed by different employees. When a process is decoupled it requires handovers from one employee to the other [14]. So a decoupled process is a process in which activities are divided into different jobs, while a coupled 
process is a process in which different activities are combined into one job [15-17, 19].

Larsson and Bowen [17] offer some guidance on choosing the level of decoupling based upon standardization of the service design. It is explained that the more standardized a service is, the more the FO and BO can be decoupled. If demand variation is high and, hence, more customization is required, more interaction between the $\mathrm{FO}$ and $\mathrm{BO}$ is needed to perform well and, hence, a coupled approach would be more appropriate.

Metters and Vargas [19] explain that decoupling could be applied to split up the FO and BO tasks of the process into different jobs, executed by different employees who are usually geographically separated. Low contact activities are then removed from the FO employee and performed by a different BO employee [20]. Oppositely, firms can also decide to keep the FO and BO tasks coupled, in which one employee covers both the FO and BO tasks. Moreover, organizations can also make different decisions regarding the coupling/decoupling of activities within the FO or within the BO. For example, one could decide to split up different BO activities over multiple employees [14]. It is shown that the decision to couple or decouple activities should be dependent on the unique characteristics of the organization.

\section{Coupling/decoupling: Impact on performance}

The (de-)coupling decision also influences operational performance. Activities can be coupled in a specific job performed by the same employee in order to provide flexible and responsive services or to reduce idle time (reduction of cost, higher productivity) [14]. When dealing with requests from patients, for example, the FO personnel of CCPs may also execute the follow-up work themselves. Furthermore, a coupled approach eliminates the risk of errors due to handovers [17], within FO or BO as well as in between the two. A coupled process in the FO benefits from the interaction with the customer [13].

Alternatively, activities can be decoupled to utilize employee expertise (high quality, customized service delivery) or to realize potential efficiency benefits (costs) [19, 20]. Decoupled processes enable centralization, specialization and counterchecks. They also offer more options for matching workers and tasks [14]. Decoupled jobs offer the opportunity to free contact personnel for sales and service delivery. For instance, professionals in the CCPs provide services, while clerical staff provide administrative support (e.g. making appointments). In general it is often assumed that decoupling benefits efficiency and reduces costs, while coupling enables the firm to offer superior service. Remarkably, Metters and Vargas [19] have shown an opposite result: it is also possible to use a decoupled approach to enhance service and to use a coupled approach to reduce costs. A coupled approach could enhance efficiency and reduce costs, because it makes sure idle time of employees in the FO is reduced, as they can work on BO activities when there is no customer arriving. Decoupling could improve service, as specialized FO and BO personnel are able to offer superior work [19].

\section{Method}

\section{Case context}

Little pre-existing theory and knowledge are available on the effect of FO/BO configurations on performance, even though this phenomenon is considered as highly relevant [13]. Therefore, an exploratory case study approach was used for this research [21-24].

This paper investigates the performance of complex front/back office configurations in three different networked organizations treating people who are affected by an acquired brain injury. Acquired Brain Injury (ABI) can occur from various causes at different ages and can lead to many different types of healthcare needs. This makes the group of patients very diverse. Hence, many healthcare providers may be involved in treatment. The development of the coordination and contact points (CCPs) over time has led to front/back office configurations that vary in the $\mathrm{ABI}$ networks.

In this study, the unit of analysis is the process of guiding clients affected by ABI to the right healthcare provider. The suitability of the chosen research context follows from the importance of the interaction with the client in this process and the very wide varying enquiries of clients requiring wide expertise.

\section{Case sampling}

This study selected cases that all set up a co-ordination and contact point to guide clients with $\mathrm{ABI}$ to the right healthcare provider based upon different types of enquiries. Inclusion criteria for the study were: (1) cases differ on the independent variable, i.e. the FO/BO configuration [25]; (2) the service is consulted minimally 50 times a year; and (3) the organization has documented its working processes in an established manner.

Table I summarizes the various characteristics of the organizations included in this case research.

\section{Data collection and coding}

Multiple sources of evidence were used for data collection to facilitate a process of triangulation [26]. The main method of data collection was semi-structured interviews. To guide the data collection, a data collection protocol [23] was formed based on the little literature available, as presented in the theoretical section. In all cases, multiple respondents were interviewed. This allowed the authors to triangulate data. In each case organization, participants were co-ordinators, FO employees and BO employees.

All interviewees approached agreed voluntarily to participate in the interviews. An interview typically lasted 45-90

Table I. Some key characteristics of the case organizations.

\begin{tabular}{lccc}
\hline $\begin{array}{l}\text { CCP/ } \\
\text { characteristics }\end{array}$ & $\begin{array}{c}\text { Number of } \\
\text { enquiries } \\
\text { in 2010 }\end{array}$ & $\begin{array}{c}\text { Total number of } \\
\text { front office } \\
\text { employees }\end{array}$ & $\begin{array}{c}\text { Total number of } \\
\text { back office } \\
\text { employees }\end{array}$ \\
\hline $\begin{array}{l}\text { Region A } \\
\text { Region B }\end{array}$ & 65 & 2 & 17 \\
Region C & 84 & 1 & 6 \\
\hline
\end{tabular}


Table II. The description of the different types of enquiries.

\begin{tabular}{lll}
\hline Type of enquiry & \multicolumn{1}{c}{ The question } & \multicolumn{1}{c}{ The answer } \\
\hline Regular enquiry & Frequently asked, clear and unambiguous & The answer is known \\
Complex enquiry & Not frequently asked, but clear and unambiguous & It is known who could give the answer \\
Very complex enquiry & Unclear and ambiguous & It is not clear who could give the answer \\
\hline
\end{tabular}

minutes. Interviews were audio-taped and transcribed verbatim for subsequent analysis. The interview texts were sent back to the interviewees after transcription to verify correctness and accuracy [27]. In total, 14 interviews were conducted.

The interviews were complemented by examination of relevant documentation (e.g. process descriptions, handbooks). Finally, each case involved three 1-day field visits to observe and experience the working processes.

Thematic analysis was used in order to generate an in-depth exploration of current working practices from a $\mathrm{FO} /$ BO configuration and performance point-of-view. To explore customer contact, (de-)coupling and performance related themes in each case study, a systematic data reduction process was followed that consisted of the following steps: reading of transcripts, segmentation of sentences and phrases, codification of text segments, generation of themes and categories and identification of relationships [28].

To code and manage the data, the qualitative analysis software MAXQDA 10 [29] was used. For each case organization, the findings were presented to key informants for validation, who then suggested minor modifications only.

\section{Measuring the operational performance of the FO/BO configurations}

In healthcare the performance indicators quality, costs and accessibility are generally used to assess the performance of a process. It is aimed to deliver high quality care, in which expenses are effective, while equal access for all people to healthcare is offered [30].

The quality performance of the healthcare process can be assessed by measuring the different components forming the functional quality, i.e. the quality of the process and by evaluating the technical quality, i.e. the quality of the result. In this study, the quality performance was based on how respondents perceived the functional and technical quality [31].

The costs that are taken into account in this analysis are the direct operational costs of offering the service and the costs of the most important support activity, i.e. the brain injury team-meeting in which it is attempted to evaluate and improve the process. As this research is focused on the operational aspect of healthcare, the costs are only measured from the viewpoint of the provider of the service. Hence, only direct healthcare costs are taken into account.

For each CCP the costs are calculated for regular, complex and very complex enquiries. First of all, all relevant process steps and the relevant cost drivers for those steps are assessed. Second, the amount of time taken for each step by each relevant employee was assessed. The number of minutes is multiplied with the hourly costs of the relevant employee.
Organizational or regional differences could make a difference for the hourly costs. However, as the choice for a certain $\mathrm{FO} / \mathrm{BO}$ configuration does not influence those differences, the same hourly costs for FO employees and experts in the brain injury team is used for all CCPs.

Accessibility can be defined as the ability for persons in need of the service, to get access to this service in time and without too many hurdles [30]. So accessibility comprises equality of access, consisting of financial accessibility, geographical accessibility and timely accessibility. This research investigated perceived accessibility and measured the speed of the enquiry process as a more concrete indicator for accessibility.

\section{Results}

First, the processes underlying the services in the three regions were mapped. The process maps allowed one to better understand who was doing which part of the job in front- or back-office and in a coupled or de-coupled way (within-case analysis). In a next step, the three regions were compared from a customer contact and (de-)coupling perspective and finally in terms of operational performance (cross-case analysis).

From the regional comparison it followed that in effect all CCPs distinguish between three types of enquiries: 'regular', 'complex' and 'very complex' enquiries. 'Regular' enquiries include routine, unambiguous questions, which can be answered in a more or less standard way. This means that the front-office employee knows very well how to help this customer. In the case that the question is not clear and there is no standard advice or referral pattern, the enquiry becomes complex or very complex. In a 'complex' enquiry, it is still clear for the FO employee who should be contacted to answer the enquiry, while this is not the case in the 'very complex' situation. In the latter case, the enquiry itself is not clear and unambiguous and needs to be tackled before a referral pattern can be discussed. The way enquiry complexity was determined is summarized in Table II.

\section{Within-case analysis}

Case 1: Region A

The activities of the Coordination and Contact Points (CCP) in region A comprises a process via which advice is provided towards clients. This process does not differ with the complexity of the enquiry. The process is graphically illustrated in Figure 1. An important part of this process is the consultation of experts for all cases. The nurse practitioner decides which experts to consult depending on the complexity and multi-disciplinarity of the question. Only for very complex enquiries all experts in the brain injury team are 

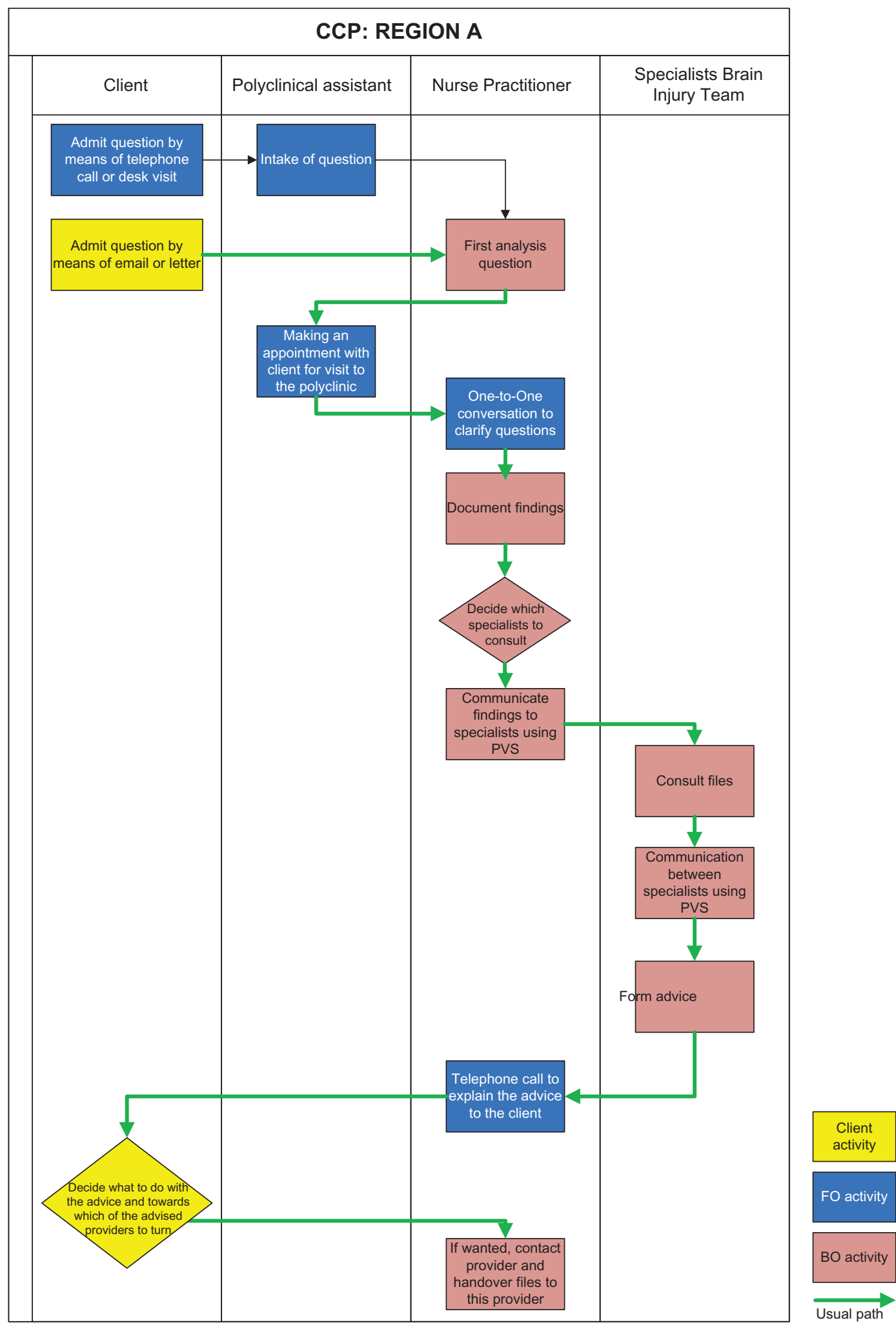

Figure 1. Process map operational process, region A.

consulted. This communication is performed electronically via a dedicated information system called PVS (PatientVolgSysteem).

\section{Case 2: Region B}

The process at the $\mathrm{CCP}$ in region $\mathrm{B}$ also aims at providing information and advice for the care of people with an acquired brain injury. However, this process differs with the complexity of the enquiry. The process is graphically illustrated in Figure 2. For regular enquiries the process is fully executed during the telephone call and the client immediately receives the advice. If enquiries become more complex, BO consultation with one specialist takes place. For very complex enquiries the question of the client is discussed during the brain injury team-meetings. Those meetings take place every 


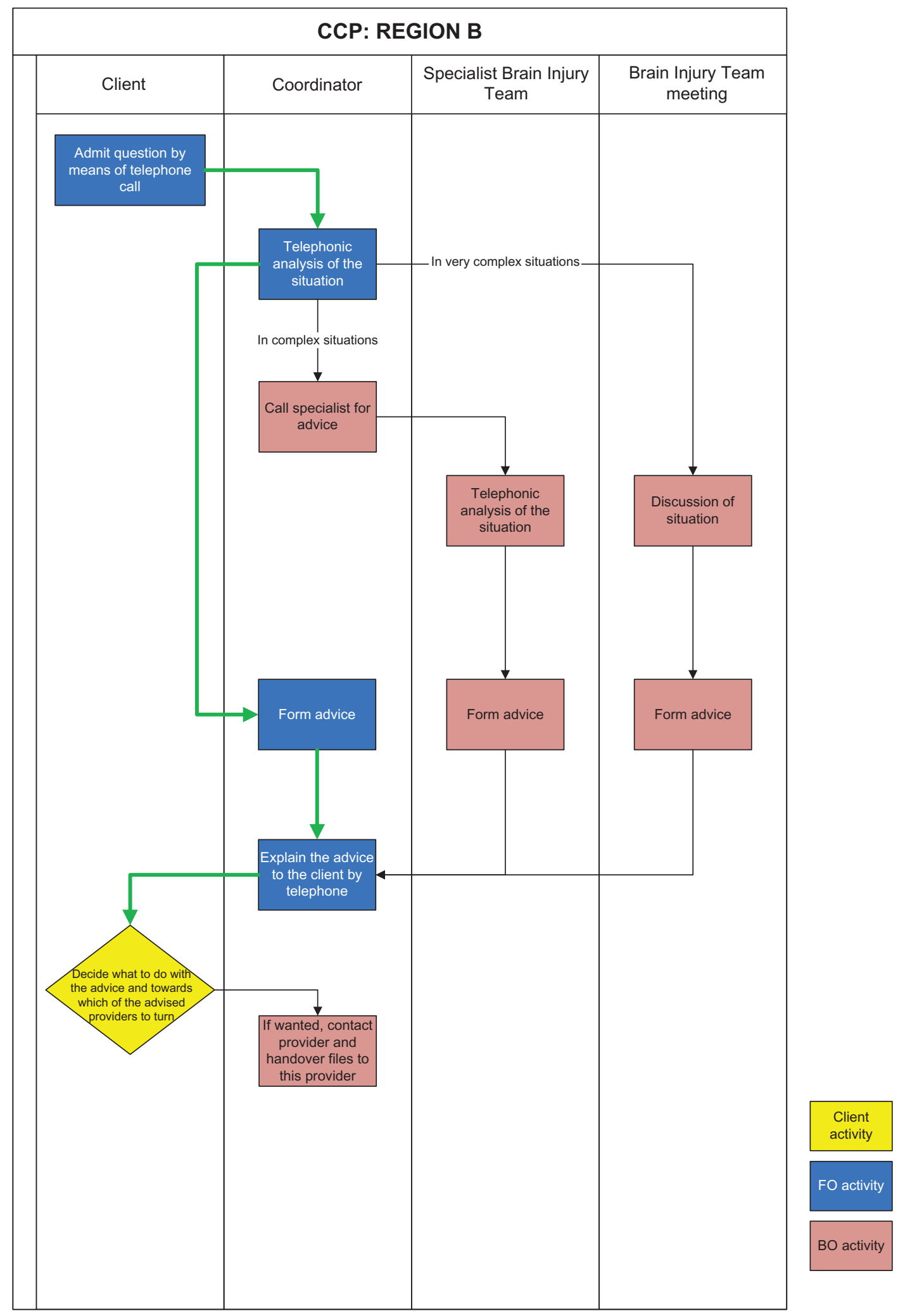

Figure 2. Process map operational process, region B.

7-8 weeks. After advice is formed in the BO, the FO employee calls the client back to explain this advice.

An additional activity is added to the process if the co-ordinator acknowledges that the client finds it difficult to explain his situation. In this case the co-ordinator offers the option to contact the healthcare provider that the client is advised to turn to.
Finally, all advice that is given to people is discussed and evaluated during the brain injury team-meetings.

\section{Case 3: Region C}

This CCP also uses three different kinds of processes depending on the complexity of the enquiries. The whole 


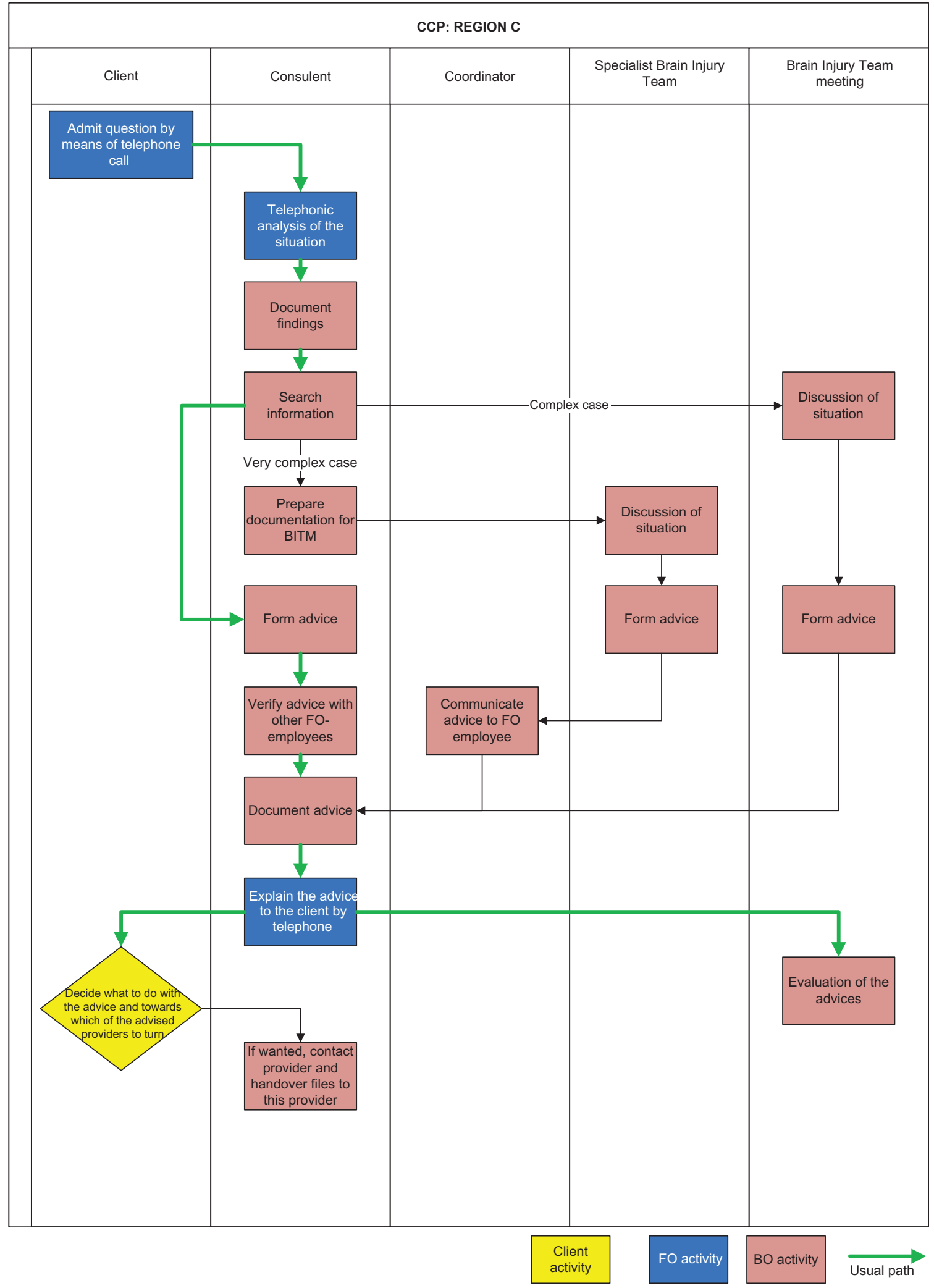

Figure 3. Process map operational process, region C.

process is graphically illustrated in Figure 3. For all complexities, the client first calls the CCP. During a 25minute phone call the enquiry of the client is assessed by a consultant. For regular enquiries, the same employee looks up more information to form advice for the client. After verification of this advice with other consultants, the client is called to explain the advice.
For more complex enquiries, $\mathrm{BO}$ consultation with one specialist takes place. Together with the specialist the consultant forms advice by telephone, which is subsequently communicated by the consultant to the client.

For very complex enquiries, the consultant documents the enquiry in a standard document to be discussed in the brain injury team-meetings. Those meetings take place 5-times a 
Table III. Comparison FO/BO configurations of CCPs of the regions.

Type of question

\begin{tabular}{lccc}
\cline { 2 - 4 } CCP & Regular enquiry & Complex enquiry & Very complex enquiry \\
\hline Region A & FO \& BO - Decoupled (IT) & FO \& BO - Decoupled (IT) & FO \& BO - Decoupled (IT) \\
Region B & FO - Coupled & FO \& BO - Decoupled (Telephone) & FO \& BO - Decoupled (Face-to-face) \\
Region C & FO \& BO - Coupled & FO \& BO - Decoupled (Telephone) & FO \& BO - Decoupled (Face-to-face) \\
\hline
\end{tabular}

year. In this meeting all specialists discuss the enquiry and together form advice. This advice is communicated to the consultant, who in turn communicates this back to the client. During those brain injury team-meetings, the advices to all other enquiries are also evaluated. The co-ordinator of the $\mathrm{CCP}$ is also present in this meeting and communicates these evaluations back to the consultants.

\section{Cross-case analysis}

\section{FO/BO configurations}

One of the major findings from the process mapping is that the process of providing information and advice for the care of people with an acquired brain injury vary with the complexity of the enquiry in region B and C. Therefore, the type of enquiry is introduced in terms of complexity in Table III, which summarizes the FO/BO configurations for the cases. If there are decoupled processes, the method of handover is shown between brackets.

This empirical research showed that, for a similar service, different $F O / B O$ configurations are applied in practice. For a regular enquiry the operational process in region $\mathrm{B}$ is designed to be fully executed in contact with the client. At the same time, in region $\mathrm{A}$ and region $\mathrm{C}$ the various activities are always split in FO and BO activities. Only for more complex enquiries, the operational process in region $\mathrm{B}$ also comprises $\mathrm{BO}$ activities.

Looking at the level of decoupling, various configuration decisions can also be observed. In region $\mathrm{B}$ and region $\mathrm{C}$ all activities are executed by the same employee for a regular enquiry (coupled). In region A, however, the activities are split up over multiple employees (de-coupled). When enquiries become more complex all regions decouple the process, so that experts can be involved in developing the advice.

Region A is the only case using a specially designed information system (IT) to hand over documents and patient information to the different employees involved in the process.

The next step in the analysis is to link the different FO/BO configurations with their operational performance in terms of costs, quality and accessibility.

\section{Costs}

The cost of serving a client varies with the complexity of the cases. For the three CCPs the average costs of serving one client are shown in Table IV.

The most important difference in this comparison is that region $\mathrm{B}$ and region $\mathrm{C}$ have substantially lower costs for regular enquiries compared to region A. However, complex and very complex enquiries are processed much cheaper in
Table IV. Costs per client.

\begin{tabular}{lcccc}
\hline & & \multicolumn{3}{c}{ Type of enquiry } \\
\cline { 3 - 5 } Region & $\begin{array}{c}\text { Average } \\
\text { costs }\end{array}$ & $\begin{array}{c}\text { Regular } \\
\text { enquiry }\end{array}$ & $\begin{array}{c}\text { Complex } \\
\text { enquiry }\end{array}$ & $\begin{array}{c}\text { Very complex } \\
\text { enquiry }\end{array}$ \\
\hline Region A & $€ 104.42$ & $€ 81.32$ & $€ 81.32$ & $€ 173.72$ \\
Region B & $€ 53.44$ & $€ 50.43$ & $€ 76.03$ & $€ 248.63$ \\
Region C & $€ 104.75$ & $€ 66.74$ & $€ 95.84$ & $€ 476.10$ \\
\hline
\end{tabular}

region A. Furthermore the average costs of region B are very low compared to the other two CCPs. This is caused by the ability of this CCP to serve many more cases as regular enquiries, as opposed to the other two CCPs. Another important finding is that the difference in costs for complex and very complex enquiries between region $\mathrm{B}$ and region $\mathrm{C}$ is mainly due to the difference in the number of experts in the brain injury team. If the number of experts would be the same the costs would be more similar.

\section{Quality}

In general all CCPs were reviewed positively regarding quality by the employees. The most important differences between the CCPs influencing the quality are the method of communication in the process with the client; whether BO experts are consulted before forming the advice; the composition of the brain injury team; and the handover method.

For regular enquiries the dissimilarity in technical quality has a bigger impact on the quality than the dissimilarity due to the different communication method. As in region A experts are consulted for each enquiry independent of its complexity, region $\mathrm{A}$ is rated best on technical quality for regular enquiries. Region $\mathrm{B}$ and region $\mathrm{C}$ are rated equal, since no important differences are found.

For complex and very complex enquiries, the dissimilarities in quality are mainly due to the difference in composition of the brain injury team as well. Furthermore, the handover by means of IT of information towards the brain injury team in region A enables it to minimize the time that experts have to invest in becoming a member of the brain injury team. Experts of various disciplines are present in the team and can be easily consulted. Therefore, region A is rated best as well regarding the quality of servicing complex and very complex enquiries.

The previous discussion makes clear that region $\mathrm{A}$ outperforms the other regions in terms of quality. Region $\mathrm{C}$ is ranked higher than region $\mathrm{B}$, because unforeseen absence of the FO employee on duty can more easily be covered in region $\mathrm{C}$ as several employees are employed for the $\mathrm{FO}$ operations. Because of the backup possibilities of staff 
Table V. Comparison of the regions in terms of operational performance ( $1=$ best and $3=$ worst performance).

\begin{tabular}{lccc}
\hline & \multicolumn{3}{c}{ Performance criteria } \\
\cline { 2 - 4 } CCP & Costs & Quality & Accessibility \\
\hline Regular enquiries & & 1 & \\
$\quad$ Region A & 3 & 2 & 3 \\
Region B & 1 & 2 & 1 \\
Region C & 2 & & 2 \\
Complex and very complex enquiries & 1 & 1 \\
Region A & 1 & 3 & 2 \\
Region B & 2 & 2 & 3 \\
Region C & 3 & & \\
\hline
\end{tabular}

available, it is likely that dependability is structurally better in region $\mathrm{C}$ compared to region $\mathrm{B}$.

\section{Accessibility}

Perceived accessibility is rated equal for all CCPs, given that no significant differences are found. However, for a regular enquiry, region $\mathrm{B}$ is ranked highest regarding speed as it delivers the advice in just 1 hour. Region $\mathrm{C}$ is ranked second, with a speed of a couple of days. Region A has the slowest process, with an average time of 3 weeks to give an advice to the client. When enquiries are complex, the process takes 4 weeks in region $\mathrm{B}$ and 5 weeks in region $\mathrm{C}$. The speed in region A is not affected by the complexity of the enquiries.

Table $\mathrm{V}$ summarizes the rankings of the three regions on the three different performance criteria: costs, quality and accessibility.

\section{Discussion}

ABI networks in the Netherlands installed CCPs that function as a central and easily accessible service for people to consult when they have questions related to $\mathrm{ABI}$. To face the challenge of helping clients with $\mathrm{ABI}$ in a timely, efficient and effective way [6], the CCPs in the ABI networks must be designed and managed in such a way that the limited resources are allocated to the right client needs. The aim of this study was to better understand how the front/back-office configuration of a CCP of an ABI-network influences the operational performance in the process of advising clients affected by an ABI. This study observed various practices in the design of the $F O / B O$ configurations, which resulted in different operational performance.

\section{Design of $\mathrm{FO} / \mathrm{BO}$ configurations}

Empirical research showed that, for a similar service, different FO/BO configurations are applied in practice. The cases investigated all made different design decisions (in terms of customer contact and coupling), resulting in different $\mathrm{FO} / \mathrm{BO}$ configurations.

First of all, different design decisions are made regarding the extent of customer contact for the activities in the operational process. For a regular enquiry the operational process in region $\mathrm{B}$ is designed to be fully executed in contact with the client. At the same time, in region $\mathrm{A}$ and region $\mathrm{C}$ the various activities are split in $\mathrm{FO}$ and $\mathrm{BO}$ activities. For more complex enquiries $\mathrm{BO}$ activities are also included in the operational process in region $\mathrm{B}$.

Looking at the level of decoupling, various configuration decisions can also be observed. In region $\mathrm{B}$ and region $\mathrm{C}$ all activities are executed by the same employee for a regular enquiry. In region $\mathrm{A}$, however, the activities are split up over multiple employees. When enquiries become more complex all regions decouple the process so that experts can be involved in developing the advice.

Regarding the level of decoupling, the empirical research is an interesting extension of Metters and Vargas [19] since the results also make clear that it is the complexity of the enquiry that determines which approach is more appropriate. In the case of complex enquiries, the level of decoupling is high in all CCPs. This allows multiple experts to be involved in the process. In the case of regular enquiries, the CCPs do have a choice: either they work in the same way as in the complex enquiries or they couple the $\mathrm{FO} / \mathrm{BO}$ activities to be able to serve the client faster and without handovers.

\section{The operational performance of the $\mathrm{FO} / \mathrm{BO}$ configurations}

In region $\mathrm{B}$ the process for regular enquiries is fully $\mathrm{FO}$ orientated, while the performance of this $\mathrm{CCP}$ rates best regarding costs. This CCP is able to work efficiently because knowledge is high enough to be able to finish everything in the FO at once. This leads to less handover of work and, thus, saves time and costs as opposed to splitting it in FO and BO work. This effect is comparable with results from research in business settings (i.e. 14 in the financial setting). Coupling under such circumstances leads to higher quality in terms of demand-orientation and fewer mistakes, while the reduction of idle time of FO personnel is beneficial from a cost perspective.

However, applying the same configuration for both regular and complex enquiries in the same $\mathrm{CCP}$ of one region (A) leads to higher costs. This is because decoupling and, thus, handing over of work to the BO with highly specialized experts is also applied for regular enquiries. This could be seen as an unnecessary allowance for complexity in the process to satisfy regular customer desires (compare Larsson and Bowen [17]). For regular enquiries this leads to higher costs than necessary.

Therefore, the choice to use one or multiple $\mathrm{FO} / \mathrm{BO}$ configurations for different types of enquiries should be seen as a trade-off between costs and quality. Contingent upon the relative importance of those two performance indicators and the faced complexity of demand, one should choose to use one or multiple FO/BO configurations for different enquiries.

\section{Conclusion}

The case method used in this research has both strengths and weaknesses. The relatively small number of cases limits the generalizability of the findings. Furthermore, the current study did not include the view of the clients. How these clients observe the working of the CCPs and how they look at their performance can be included in further research.

This study used the cases to provide a richer understanding of a new phenomenon and to explore related extensions to 
existing theory. The case-based research has yielded insights to advance the development of theory on $\mathrm{FO} / \mathrm{BO}$ configurations and is one of the first studies to link these configurations to the operational performance in healthcare provision in terms of quality, costs and accessibility.

By applying the $\mathrm{FO} / \mathrm{BO}$ theory in the context of the design of CCPs for patients affected by an ABI, the authors were able to illustrate how the field of operations management (OM) can contribute to the search for efficient and effective answers to clients' needs and wants. More specifically, this study showed that the approach where experts in the back-office are always consulted is the best performing for complex and very complex enquiries. However, this way of working is not efficient for regular enquiries and takes too much time, even when a dedicated information system is used. This could be solved by further elaborating the information system into a knowledge management system. Such a system allows capturing answer and referral patterns for different enquiries. For more frequently asked regular enquiries, this can lead to a database of standard answers which can be used by the FO employee to give direct advice during the telephone call. Because the knowledge database is fed by the experts in the back-office, the FO employee always has the guarantee to work with up-to-date information, which is a guarantee for the level of quality. Further research in both healthcare and the broad field of services can test the effectiveness of this way of working and by doing so will shed more light on how demand-based and responsive care can be delivered in a costeffective way.

\section{Acknowledgements}

The authors are grateful to Koen van den Oever, Lisette Schipper and Roger Schroeder for critical comments and useful suggestions on earlier drafts of this paper.

\section{Declaration of interest}

The authors report no conflicts of interest. The authors alone are responsible for the content and writing of the paper.

\section{References}

1. Burke DC. Models of brain injury rehabilitation. Brain Injury 1995; 9:735-743.

-2. Ouwens M, Wollersheim H, Hermens R, Hulscher M, Grol R. Integrated care programmes for chronically ill patients: A review of systematic reviews. International Journal for Quality in Health Care 2005;17:141-146.

3. Lamontagne M, Swaine BR, Lavoie A, Champagne F, Marcotte AC. Perception of traumatic brain injury network participants about network performance. Brain Injury 2010;24:812-822.

4. Lamontagne M, Swaine BR, Lavoie A, Careau EA. Analysis of the strengths, weakness, opportunities and threats of the network form of organization of traumatic brain injury service delivery system. Brain Injury 2011;25:1188-1197.

5. Hersenstichting Nederland, Den Haag, 2013. https://www.hersenstichting.nl/alles-over-hersenen/hersenletselteams.html, accessed 2 July 2013.
6. Vander Laane R, Brandys C, Sullivan I, Lemsky C. Integration through a city-wide brain injury network and best practices project. NeuroRehabilitation 2001;16:17-26.

-7. Young T, Brailsford S, Connell C, Davies R, Harper P, Klein JH. Using industrial processes to improve patient care. British Medical Journal 2004;328:162-164.

8. Bohmer RMJ. Medicine's service challenge: Blending custom and standard care. Health Care Management Review 2005;30: 322-330.

9. Fredendall LD, Craig JB, Fowler PJ, Damali U. Barriers to swift, even flow in the internal supply chain of perioperative surgical sevices departement: A case study. Decision Sciences 2009;40: 327-349.

10. Hanne T, Melo T, Nickel S. Bringing robustness to patient flow management through optimized patient transports in hospitals. Interfaces 2009;39:241-255.

11. Patrício L, Fisk RP, Falcão e Cunha J. Designing multi-interface service experiences. Journal of Service Research 2008;10:318-334.

12. Frei FX. Breaking the trade-off between efficiency and service. Harvard Business Review 2006;84:93-101.

13. Broekhuis M, De Blok C, Meijboom B. Improving client-centred care and services: The role of front/back-office configurations. Journal of Advanced Nursing 2009;65:971-980.

14. Zomerdijk LG, De Vries J. Structuring front office and back office work in service delivery systems. International Journal of Operations \& Production Management 2007;27:108-131.

15. Chase RB. Where does the customer fit in a service operation? Harvard Business Review 1978;56:137-142.

16. Chase RB, Tansik DA. The customer contact model for organization design. Management Science 1983;29:1037-1050.

17. Larsson R, Bowen DE. Organization and customer: Managing design and coordination of services. Academy of Management Review 1989;14:213-233.

18. Chase RB, Northcraft GB, Wolf G. Designing high-contact service systems: Application to branches of a savings and loan. Decision Sciences 1984;15:542-556.

19. Metters R, Vargas V. A typology of de-coupling strategies in mixed services. Journal of Operations Management 2000;18:663-682.

20. Metters R, Vargas V. Organizing work in service firms. Business Horizons 2000;43:23-32.

21. Bensabat I, Goldstein DK, Mead M. The case research strategy in studies of information systems. MIS Quarterly 1987;11:369-386.

22. Meredith J. Building operations management theory through case and field research. Journal of Operations Management 1998;16: 441-454.

23. Yin RK. Case study research. 3rd ed. Thousand Oaks, CA: Sage Publications Inc; 2003.

24. Voss C, Tsikriktsis N, Frohlich M. Case research in operations management. International Journal of Operations and Production Management 2002;22:195-219.

25. Swanborn PG. Case study research. London: Sage Publications Ltd; 2010.

26. Eisenhardt KM. Building theories from case study research. Academy of Management Review 1989;14:532-550.

27. Johnston WJ, Leach MP, Liu AH. Theory testing using case studies in business-to-business research. Industrial Marketing Management 1999;28:201-213.

28. Miles MB, Huberman AM. Qualitative data analysis: An expanded sourcebook. 2nd ed. Thousand Oaks, CA: Sage Publications Inc; 1994.

29. Maxqda 10. The art of text analysis [VERBI GmBH, Berlin, 2013]. Available online at: http://www.maxqda.com/downloads/documents, accessed 2 July 2013.

30. Westert GP, Van den Berg MJ, Zwakhals SLN, Heijink R, De Jong JD, Verkleij H. De prestaties van de Nederlandse zorg. Bilthoven: Rijksinstituut voor Volksgezondheid en Milieu; 2010.

31. Grönroos CA. Service quality model and its marketing implications. European Journal of Marketing 1984;18:36-44. 